\title{
Collision tumor of the urinary bladder comprising Large cell neuroendocrine carcinoma and adenocarcinoma
}

\begin{abstract}
Large cell neuroendocrine tumors of the bladder are rare tumors. Their co-association with adenocarcinoma is even rarer. We present a third undisputed case of collision tumor comprising large cell neuroendocrine carcinoma and adenocarcinoma of the urinary bladder in a 73-year-old gentleman with a revisit to its origin and histogenesis.
\end{abstract}

Keywords: Adenocarcinoma, bladder, neuroendocrine

\section{INTRODUCTION}

Large cell neuroendocrine carcinoma (LCNEC) of urinary bladder is a rare entity and its association with adenocarcinoma makes it extremely rare. We found only two cases of LCNEC of urinary bladder associated with adenocarcinoma in the world literature..$^{[1-3]}$ Till date, 17 cases of LCNEC have been reported with approximately half of the cases being associated with other histological components ${ }^{[4]}$ Primary adenocarcinoma of urinary bladder itself is an uncommon tumor comprising $<2 \%$ of all primary vesical malignant neoplasms. ${ }^{[1,5]}$

The presence of high-grade neuroendocrine carcinoma moderates a poor prognosis and hence it is of importance to recognize the divergent differentiation which in turn can alter patient's management and prognosis. We present the third case in the English literature of primary LCNEC associated with adenocarcinoma with clinical, histological, and immunohistochemistry (IHC) findings.

\section{CASE REPORT}

A 73-year-old male, smoker with no significant past and family history presented with complaints of hematuria for 15 days. Routine laboratory investigations were unremarkable. Abdominal ultrasonography and computed tomography scan revealed a bladder mass measuring $5.6 \mathrm{~cm} \times 2.4 \mathrm{~cm}$ with

\begin{tabular}{|l|c|}
\hline \multicolumn{2}{|c|}{ Access this article online } \\
\hline \multirow{2}{*}{$\begin{array}{l}\text { Website: } \\
\text { www.asjo.in }\end{array}$} & Quick Response Code \\
\hline \multirow{2}{*}{$\begin{array}{l}\text { DOI: } \\
\text { 10.4103/ASJO.ASJO_14_16 }\end{array}$} & \\
&
\end{tabular}

significant bilateral pelvic lymphadenopathy. Transurethral resection of bladder tumor was performed which showed features of poorly differentiated carcinoma infiltrating muscularis propria. Above-mentioned findings led to radical cystoprostatectomy with bilateral pelvic lymph node dissection and resection of a sigmoid colon serosal deposit which was evident intraoperatively.

Grossly, cystoprostatectomy specimen measured $12 \mathrm{~cm} \times 10 \mathrm{~cm} \times 9 \mathrm{~cm}$. On cut section, tumor measured $6 \mathrm{~cm} \times 4.5 \mathrm{~cm} \times 3 \mathrm{~cm}$, involving predominantly posterior wall and dome. Tumor was grossly infiltrating full thickness of the bladder wall extending into the perivesical fat. Hematoxylin and eosin-stained sections showed predominant areas comprising diffuse sheets of large neoplastic cells having moderate to high $\mathrm{N}: \mathrm{C}$ ratio, coarse granular chromatin, conspicuous nucleoli, and moderate amount of eosinophilic cytoplasm. Significant necrosis and brisk mitosis (15-17/10 high power field in most mitotically active area) was evident

\section{Jatin Sundersham Gandhi, Sunil Pasricha, GURUdUTT GUPTA}

Department of Pathology, Rajiv Gandhi Cancer Institute and Research Centre, New Delhi, India

Address for correspondence: Dr. Jatin Sundersham Gandhi, Department of Pathology, Rajiv Gandhi Cancer Institute and Research Centre, Rohini, New Delhi - 110 085, India. E-mail: jgandhi58@gmail.com

This is an open access article distributed under the terms of the Creative Commons Attribution-NonCommercial-ShareAlike 3.0 License, which allows others to remix, tweak, and build upon the work non-commercially, as long as the author is credited and the new creations are licensed under the identical terms.

For reprints contact: reprints@medknow.com

How to cite this article: Gandhi JS, Pasricha S, Gupta G. Collision tumor of the urinary bladder comprising Large cell neuroendocrine carcinoma and adenocarcinoma. Asian J Oncol 2017;3:144-6. 
[Figure 1a]. Associated with this, the second component (20\%) of collision tumor was identified comprising well-differentiated adenocarcinoma of enteric type [Figure $1 \mathrm{~b}-\mathrm{d}$ ]. The overlying and surrounding urothelium shows intestinal metaplasia with moderate dysplasia.

IHC stains were performed in most cases, using the automated Ventana ES, using ready-to-use antibodies. IHC studies showed positivity for cytokeratin (CK), CK7, synaptophysin [Figure 2a], thyroid transcription factor-1 (TTF-1) [Figure 2b], CD56, and chromogranin A in diffuse poorly differentiated tumor cells. These cells were negative for $\mathrm{p} 63$, thrombomodulin, carcinoembryonic antigen (CEA), CDX2, and CK20. The adenocarcinoma cells were strongly positive for CEA [Figure 2c], CK7, epithelial membrane antigen, and CDX2. On extensive sampling with histomorphological and IHC workup, no urothelial differentiation could be demonstrated. Hence, a final diagnosis of LCNEC associated with primary adenocarcinoma of urinary bladder was rendered. Sections from serosal deposit over sigmoid colon showed tumor deposit of LCNEC. Nine out of thirteen right pelvic lymph nodes and three out of eight left pelvic lymph nodes showed metastatic tumor deposit of LCNEC with extracapsular extension. Prostate and seminal vesicles were free of tumor and urethral cut end margin was free. The patient was advised adjuvant chemotherapy, but he refused for the same and expired after 4 months postsurgery.

\section{DISCUSSION}

Neuroendocrine carcinomas of urinary bladder are uncommon and include carcinoids, small cell neuroendocrine carcinomas (SCNEC), and LCNEC with majority comprising

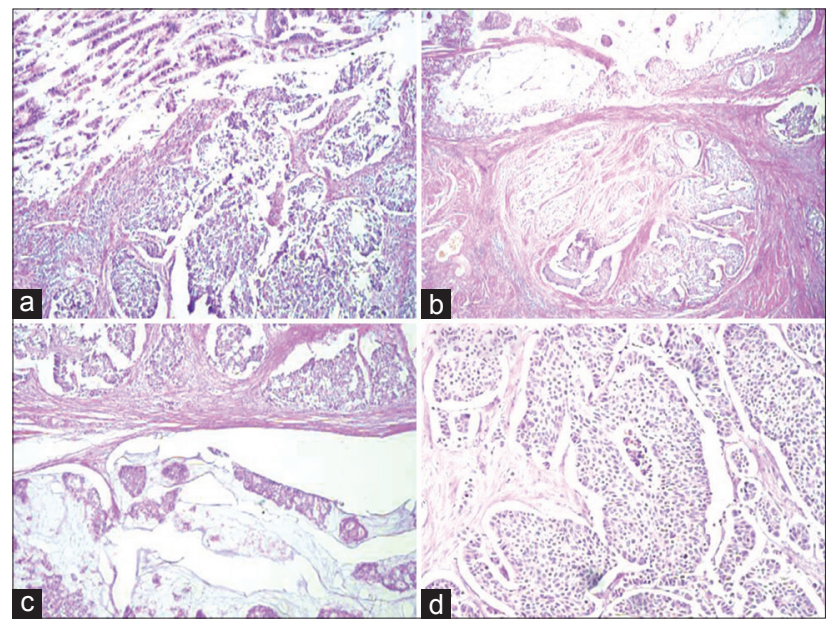

Figure 1: (a) section showing areas of large cell neuroendocrine carcinoma ( $H$ and $E, \times 200$ ). (b-d) section showing a collision tumor comprising enteric-type adenocarcinoma and large cell neuroendocrine carcinoma of urinary bladder $(\mathrm{H}$ and $\mathrm{E}, \times 100)$
SCNEC. The rarest type is LCNEC with only 17 cases reported in the literature. The diagnosis of LCNEC is based on criteria established for these tumors in lung which includes (a) large cells with relatively low $\mathrm{N}: \mathrm{C}$ ratio, (b) coarse chromatin and frequent nucleoli, (c) mitotic activity in excess of 10/10 hpf with areas of comedonecrosis, (d) IHC or ultrastructural evidence of neuroendocrine differentiation. ${ }^{[2,3]}$

Regarding their histogenesis, various theories have been proposed, but the most plausible explanation is origin from multipotential undifferentiated stem cells within the normal urothelium, which also explains the presence of neuroendocrine and glandular elements in our presented case. $^{[1,2]}$ The etiology, natural history, prognosis, clinical features, and therapeutic implications of LCNEC are similar to that of SCNEC. ${ }^{[3]}$ Case reports demonstrating coexistent adenocarcinoma across the complete spectrum of neuroendocrine tumors of urinary bladder support the origin from multipotential undifferentiated stem cells with normal urothelium. ${ }^{[2]}$

Zaghloul et al..$^{[5]}$ studied 142 cases of adenocarcinoma of urinary bladder and classified them into 5 histologic subtypes: enteric (papillary), mucinous, signet ring, adenocarcinoma not otherwise specified (NOS), and mixed. The presented case had histomorphology of adenocarcinoma NOS type. Papillary and NOS types had a statistically significant higher 5-year disease-free survival compared to patients with mucinous or signet ring histological subtypes although extent of tumor infiltration and nodal involvement have major effect on disease-free survival. In relation to management and prognosis, pure LCNEC or pure adenocarcinoma of urinary

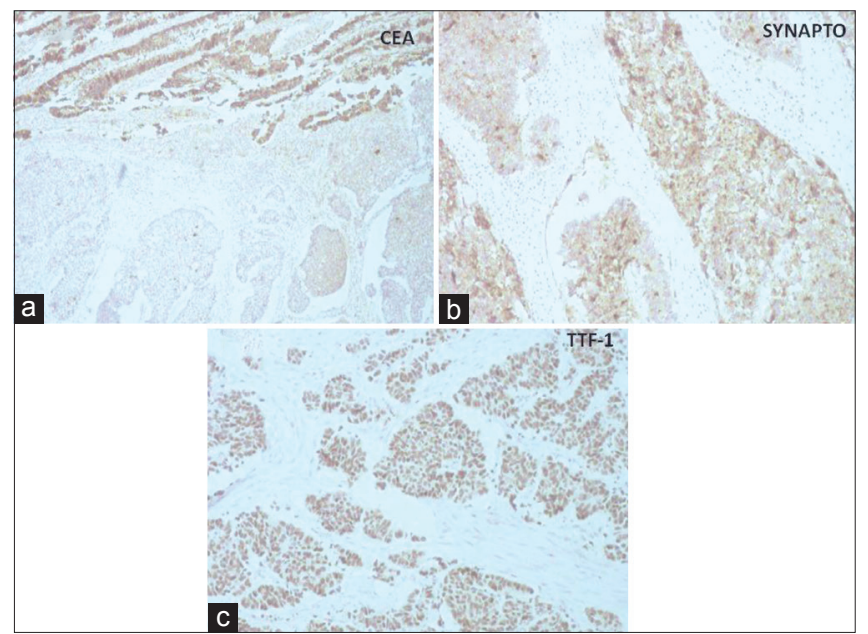

Figure 2: (a) section showing synaptophysin positivity in large cell neuroendocrine carcinoma areas $(D A B, \times 100)$. (b) section showing thyroid transcription factor-1 positivity in large cell neuroendocrine carcinoma areas $(D A B, \times 100)$. (c) section showing carcinoembryonic antigen positivity in areas of enteric type adenocarcinoma (DAB, $\times 100)$ 
bladder have a poorer prognosis as compared to the conventional urothelial carcinoma and this rare composite tumor is associated with dismal prognosis. ${ }^{[1,4]}$ Since there have been only 17 reported cases of LCNEC of urinary bladder, the biological behavior of this entity remains to be determined and the role of surgery/chemotherapy in the treatment of LCNEC of the urinary bladder is not clear. However, several small studies of pulmonary LCNEC have reported a relatively high objective response rate to standard chemotherapeutic regimens applied for the treatment of SCNEC. Based on the present data, LCNEC although associated with poor prognosis, early diagnosis, and timed treatment with adjuvant chemotherapy besides cystoprostatectomy may provide long-term control if the tumor is localized. ${ }^{[3]}$ However, in the presented case, patient refused for adjuvant chemotherapy and expired after 4 months postsurgery. Hence, it is imperative to be aware of varied differentiations that can be encountered in urinary bladder carcinoma and appropriate diagnostic methods should be carried out to categorize it properly as some of them may have prognostic and therapeutic implications. ${ }^{[2]}$
Financial support and sponsorship

Nil.

Conflicts of interest

There are no conflicts of interest.

\section{REFERENCES}

1. Abenoza P, Manivel C, Sibley RK. Adenocarcinoma with neuroendocrine differentiation of the urinary bladder. Clinicopathologic, immunohistochemical, and ultrastructural study. Arch Pathol Lab Med 1986;110:1062-6.

2. Evans AJ, Al-Maghrabi J, Tsihlias J, Lajoie G, Sweet JM, Chapman WB. Primary large cell neuroendocrine carcinoma of the urinary bladder. Arch Pathol Lab Med 2002;126:1229-32.

3. Bertaccini A, Marchiori D, Cricca A, Garofalo M, Giovannini C, Manferrari F, et al. Neuroendocrine carcinoma of the urinary bladder: Case report and review of the literature. Anticancer Res 2008;28:1369-72.

4. Tsugu A, Yoshiyama M, Matsumae M. Brain metastasis from large cell neuroendocrine carcinoma of the urinary bladder. Surg Neurol Int 2011;2:84.

5. Zaghloul MS, Aziz SA, Nouh A, Mouhran TZ, El-Shazely S, Saber A. Primary adenocarcinoma of the urinary bladder: Risk factors and value of postoperative radiotherapy. J Egypt Natl Canc Inst 2003;15:193-200. 